\title{
Knowledge of Breast Cancer Symptoms, Risk Factors, Preventive Measures and Management among Students in University of Uyo
}

\author{
Grace Enomfon Akpan*, Emem Abatai \\ Department of Physical and Health Education, University of Uyo, Nigeria
}

*Corresponding Author: Grace Enomfon Akpan, Department of Physical and Health Education, University of Uyo, Nigeria

\begin{abstract}
The purpose of the study was to assess the level of knowledge of breast cancer among students of the University of Uyo. Four objectives, four research questions and four hypotheses were formulated to guide the study. The design for the study was descriptive survey. A sample size of 300 undergraduate students was selected using non-proportionate sampling technique. Data collection was done with self-constructed questionnaire which was face validated by two lecturers from the department and one lecturer from test and measurement unit, department of educational foundation, guidance and counseling and my supervisor. A reliability coefficient of .91 was obtained from the responses of 30 students at Akwa Ibom State University, Ikot Akpaden. Data collected were analyzed using percentages to answer research questions and chi-square statistics to test the null hypothesis. At the end of the analysis, it was discovered that knowledge of breast cancer management approaches is significantly higher (70.7\%) among students in University of Uyo. Students possessed low level of knowledge of breast cancer risk factors (37.6\%) and their knowledge of breast cancer symptoms and preventive measures was average (50.2\% and $66.2 \%)$ respectively. Based on the findings, it was recommended that health education on breast cancer should be incorporated in general studies courses (GSTS), students should be advised on Breast Self-Examination (BSE), school management and NGOs should from time to time equip hospitals with machines to help in breast screening and this should be made affordable and accessible to all individuals.
\end{abstract}

Keywords: Breast Cancer Symptoms, Risk Factors and Preventive Measures, Uyo

\section{INTRODUCTION}

Breast cancer is the commonest of all cancers and one of the major threats to health especially among women (Lakeshore Cancer Centre, 2014). Report on the incidence of breast cancer reveals that one out of every eight women in the world stand a chance of having the disease in her lifetime (American Cancer Society, 2015). Although the incidence of breast cancer is increasing all over the world, the rate of increase is reportedly higher in developing countries where late detection of disease is common (World Health Organization, 2015). Most of this increase in incidence of breast cancer is as a result of changes in lifestyle which puts individuals at a risk of developing the disease. Breast cancer in African women tends to occur in pre-menopausal women with a peak incidence between the ages of 35 and 45 years (Somdyala, Bradshaw, Gelderblom and Parkin, 2010) and mortality rates for African Women are relatively higher when compared to women in Western countries (Fragen \& Newman, 2015).

American Cancer Society (2015-2016) described breast cancer as a group of diseases that cause cells in the breast to change and grow out of control and that breast cancer beg9ins in the breast tissue that is made up of glands for milk production, called lobules, and the duct that connect the lobules to the nipple. The disease of breast cancer has posed a serious problem in Nigeria. A major worry about breast cancer in Nigeria is the continuous rise in the number of cases and deaths (Cancer Epidemiology, 2012), a situation which confirms lakeshore cancer centre prediction that breast cancer may rise to 42 million by 2020 in both males and females in the country. Ep9idemiological studies have identified a number of risk factors that are associated with increased risk of a woman developing breast cancer. Lester in 2007, observed that the notable risk factors for breast cancer include age (age at menarche, first child birth and menopause). Parity; use of contraceptive pills and null parity. Previous thoracic radiation therapy and the use of hormones with history of present or past use of 
estrogen and progesterone, body mass index, alcohol consumption, diet and physical activity are also implicated. The behavior and lifestyle mentioned above is common among young single ladies, majority of whom are in higher institutions. Nwaneri A, Osuala E. O, Okpala P. U, Emesowum A. C \& Iheanacho in 2017 reported that the awareness of breast cancer increased with increase in educational attainment. In their study, one hundred and four (29.8\%) respondents showed that breast cancer is an illness caused by ancestral forces. $58.2 \%, 51.9 \%$ and $38.2 \%$ identified lump, swelling and redness of nipple respectively as symptoms of breast cancer. On the knowledge of risk factors for breast cancer, $181(51.9 \%)$ reported that family history of breast cancer was a risk factor. $125(35.8 \%)$ and $72(20.6 \%)$, indicated that not breastfeeding and late age at first child birth respectively were risk factors for breast cancer.

Breast cancer symptoms are varied and includes some of the following among others - painless lump, redness of the skin, breast pain/heaviness etc. Most individuals have little or no idea of breast cancer symptoms and as such will likely not take any action until the disease has reached an advanced stage. This is one of the major reasons for poor prognosis and increased mortality. However, breast cancer is essentially preventable. Early detection of lumps is one of the surest means of breast cancer prevention. In Western countries, breast cancer screening is usually done using mammograms. However, the use of mamograms is limited and inaccessible to most women in Africa (Panieri, 2010). In the absence of readily available mammographic screening facility, breast self-examination despite its known limitations, remain viable and practical alternative for African women (Panieri, 2010). Most women do not have knowledge of breast self-examination, the benefits and how to perform it effectively. Irurhe N. K, Raji S. B., Olowoyeye A. O, Adeyomoye R. A et al in 2012 reported that there was low level of knowledge of breast cancer among population they studied. $48.5 \%$ of the respondents had no idea that breast cancer be managed. Although majority of the respondents had heard of Breast Self Examination, they had low level of knowledge of how and when to carry out Breast Self Examination. On their knowledge of who breast cancer can affect, 48.5\% said it affects anybody with family history of breast cancer and some said it affect women who do not breastfeed their children.

There are various approaches to the management of breast cancer. This includes surgery, radiation therapy and chemotherapy. Patients in Africa (including Nigeria) often present with an advanced stage of the disease which usually result in poor prognosis. According to the American Cancer Society (2013-2014), treatment decisions are made by the patient and the physician after a consideration of the cancer, patient age, and the risk and benefits associated with each treatment protocol. However, most individuals display lack of knowledge on the management strategies of breast cancer and belief that surgery is the only option. A study by Omaka-Amari L. N., Ilo C. I, nwimo I. O, Onwunaka C \& Umoke C. I. in 2015 revealed that women's knowledge of breast cancer was average in all the components assessed (knowledge of breast cancer symptoms, risk factors, prevention and treatment options) except for treatment centers where the women demonstrated high knowledge. $55 \%$ had knowledge of breast cancer symptoms, $42 \%$ knew of the risk factors associated with breast cancer. On the knowledge of breast cancer preventive measures, 57\% responded correctly and $52 \%$ had knowledge of breast cancer treatment options. However, the respondents demonstrated high knowledge $(60 \%)$ of treatment centers for breast cancer. The result of the study showed that the participants' overall knowledge $(49 \%)$ of breast cancer was average. In order to make informed decisions for the management of breast cancer, individuals should possess knowledge of these management options. Since breast cancer affects African women at an early age, it is necessary to assess individual's level of knowledge of breast cancer symptoms, risk factors, preventive measures and management strategies. This will be done with a view to providing information that will be useful in addressing the problem of breast cancer.

\subsection{Statement of the Problem}

Breast cancer has claimed the lives of many women in Nigeria. The world health organization (WHO) on 2017 world health day noted that over 8.8 million cancer deaths were recorded globally yearly out of which an estimated 80,000 are Nigerians. According to WHO statistics, breast cancer kills about 40 Nigerians daily. A recent study on the distribution of cancer in Akwa Ibom State showed that breast cancer is one of the most commonest cancers diagnosed in both males and females after lung cancer. This makes the problem alarming and worrisome. The main reason for this increasing mortality rate is 
due to late detection of the disease. This factor is invariably a direct consequence of widespread low level knowledge of breast cancer symptoms, risk factors and preventive measures observed in Nigeria. In view of the upsurge in the case of breast cancer and mortality rates, it is necessary to assess the knowledge of individuals about breast cancer to provide information that will be useful in planning awareness programmes. Hence, the study to determine the level of knowledge of breast cancer symptoms, risk factors, preventive measures and management approaches among students in the University of Uyo will not be out of place.

\subsection{Objectives of the Study}

The purpose of the study was to assess the level of knowledge of breast cancer among students of the University of Uyo. Specifically, the study seeks to achieve the following objectives:

- find out students' knowledge of breast cancer symptoms

- find out students' knowledge of breast cancer risk factors

- find out students' knowledge of breast cancer preventive measures

- find out students' knowledge of breast cancer management approaches

\subsection{Research Questions}

The following research questions were formulated for the study:

- What is the level of knowledge of breast cancer symptoms among students?

- What is the level of knowledge of breast cancer risk factors among students?

- What is the level of knowledge of breast cancer preventive measures among students?

- What is the level of knowledge of breast cancer management strategies among

students?

\subsection{Research Hypotheses}

The following research hypotheses were formulated to guide this study:

- Knowledge of breast cancer symptoms is not significant among students in University of Uyo.

- Breast cancer risk factors are not significantly known by students in University of Uyo.

- Knowledge of breast cancer preventive measures is not significant among students in University of Uyo.

- Knowledge of breast cancer management approaches is not significant among students in University of Uyo.

\section{METHODS}

This is a detailed procedural description of the research method used to achieve the objectives of the study which is geared towards assessing the level of knowledge of breast cancer among students in the University of Uyo. It will be discussed under research design, population for the study, sample and sampling technique, instrument for data collection, validity of the instrument, reliability of the instrument, method of data collection and method of data analysis.

\subsection{Research Design}

This study adopted a descriptive survey research design. Amajuoyi and Joseph (2016) described survey research design as one in which a group of people or items is studied by collecting and analyzing data from only a few people or items considered to be a representative of the entire group. The choice of this design therefore is to examine the knowledge of breast cancer risk factors, symptoms, preventive measures and management strategies among sampled students in University of Uyo considered to be the representatives of the entire population.

\subsection{Population of the Study}

The population in focus consisted of all regular undergraduate students in the University of Uyo irrespective of their faculty, department or level of study. The total number of students from the 
Knowledge of Breast Cancer Symptoms, Risk Factors, Preventive Measures and Management among Students in University of Uyo

university database was 21,453 as from the beginning of first semester 2017/2018 session (Uniuyoportal, 2018).

\subsection{Sample and Sampling Technique}

A sample size of 300 students was randomly selected from three faculties out of the twelve faculties existing in University of Uyo. The 3 selected faculties represent each of the 3 campuses i.e. Annex, Town and Main Campuses. A non-proportionate stratified sampling technique was used to select the faculties from which the respondents were sampled. This technique was employed because University of Uyo operates multi-campuses system of main campus, annex campus and town campus. Therefore, there is need for these campuses to be adequately represented. The three selected campuses include faculties of Agriculture, Science and Education. The researcher randomly selected 10 students from each of the selected faculties to respond to the instrument.

\section{INSTRUMENT FOR DATA COLLECTION}

A self-constructed questionnaire was used to collect date for the study. The questionnaire consists 28 items spread over 5 sections (A-E). Section A will elicited demographic data and embodied three questions relating to age, sex and marital status. Section B, C, D and E includes series of items of yes and no options covering knowledge of breast cancer risk factors, preventive measures, symptoms and management approaches respectively.

\subsection{Validity of Instrument}

The instrument, a structured questionnaire was face-validated by an expert in the field of assessment from Department of Educational Foundations, Guidance and Counselling and two lecturers in the Department of Physical and Health Education all from the University of Uyo. Their criticisms and suggestions and that of my Supervisor formed the final draft of the instrument used.

\subsection{Reliability of Instrument}

To establish the reliability of the instrument, a pilot study was carried out where 30 copies of the instrument were administered to 30 students at Akwa Ibom State University, Ikot Akpaden. Reliability co-efficient of .91 was obtained using inter-rater statistics.

\subsection{Method of Data Collection}

The questionnaires were administered by the researcher and one assistant who were briefed on the sample population before the day. Ample time was given to respondents to fill the questionnaire. Necessary explanations and clarifications were made to guide their responses.

\subsection{Method of Data Analysis}

Data collected were organized and analyzed using simple percentages to answer the research questions and chi-square statistics to test the null hypotheses.

\section{Presentation of Data}

Table1: Frequency and Percentages Demographic Information of the Sample

\begin{tabular}{|l|l|l|l|}
\hline \multicolumn{1}{|c|}{ Variable } & \multicolumn{1}{|c|}{ Categories } & \multicolumn{1}{c|}{ Frequency } & Percentage (\%) \\
\hline Gender & Male & 142 & 49.8 \\
\hline & Female & 143 & 50.2 \\
\hline Age & $16-20$ & 91 & 31.9 \\
\hline & $21-25$ & 110 & 38.6 \\
\hline & $26-30$ & 42 & 14.7 \\
\hline & $31-35$ & 22 & 7.7 \\
\hline Marital Status & 35 and above & 20 & 7.0 \\
\hline & Single & 235 & 82.5 \\
\hline
\end{tabular}

Table 1 showed the respondents which considered 142 (49.8\%) male and 143 (50.2\%) female; the age range distributions were 16-20 years 91 (31.9\%), 21-25 years 110 (38.6\%), 26-30 years $42(14.7 \%)$, $31-35$ years $22(7.7 \%)$ and 36 years plus $20(7.0 \%)$, distributions according to marital status were single $235(82.5 \%)$ and married $50(17.5 \%)$. 
Knowledge of Breast Cancer Symptoms, Risk Factors, Preventive Measures and Management among Students in University of Uyo

\subsection{Percentage Analysis Of Research Questions}

\section{Research Question 1}

What is the level of knowledge of breast cancer symptoms among student?

Table2: Percentage Analysis of Knowledge of Breast cancer Symptoms among Students in University of Uyo

\begin{tabular}{|l|l|l|l|l|l|}
\hline S/N & \multicolumn{1}{|c|}{ Items } & \multicolumn{1}{|c|}{ Yes } & \multicolumn{1}{|c|}{$(\boldsymbol{\%})$} & \multicolumn{1}{|c|}{ No } & \multicolumn{1}{|c|}{ (\%) } \\
\hline 1. & Painless lump is a symptoms of breast cancer & 145 & $50.9 \%$ & 140 & $49.1 \%$ \\
\hline 2. & Redness of the skin of the breast is a symptom of breast cancer & 177 & 52.1 & 108 & $37.9 \%$ \\
\hline 3. & Breast pain and heaviness is a symptom of breast cancer & 172 & 60.4 & 113 & 38.7 \\
\hline 4. & Swelling of the breast is a symptom o f breast cancer & 162 & 56.9 & 123 & 43.2 \\
\hline 5. & Thickening in the breast is a symptom of breast cancer & 137 & 48.1 & 148 & 51.9 \\
\hline 6. & Soreness of the nipples is a symptom of breast cancer & 148 & 52.0 & 137 & 48.1 \\
\hline & Total & $\mathbf{9 4 1}$ & $\mathbf{5 5 . 1 \%}$ & $\mathbf{7 6 9}$ & $\mathbf{4 5 . 0}$ \\
\hline
\end{tabular}

The table able shows that there is an average level of knowledge of breast cancer symptoms among students in University of Uyo $941(55.1 \%)$. It shows that $145(50.9 \%)$ knew that painless lump is a symptom of breast cancer, while 140 (49.1\%) did not know, 177 (62.1\%) said redness of the skin of the breast is a symptom of breast cancer, $108(37.9 \%)$ said no, another 172 knew breast pain and heaviness is a s symptom of breast cancer, $113(39.7 \%)$ do not know, 162 (56.9\%) knew that swelling of the breast is a symptom of breast cancer while 123 (43.2\%) do not know, 137 (48.1\%) knew that thickening in the breast is a symptom of breast cancer, 148 (51.9\%) however answered no and 148 $(52.0 \%)$ knew that soreness of the nipples is a symptom of breast cancer.

Research Question 2: What is the level of knowledge of Breast Cancer Risk Factors among students in University of Uyo?

Table3: Percentage Analysis of Knowledge of Breast Cancer Risk Factors among Students in University of Uyo.

\begin{tabular}{|l|l|l|l|l|l|}
\hline $\mathbf{S} / \mathbf{N}$ & \multicolumn{1}{|c|}{ Items } & \multicolumn{1}{|c|}{ Yes } & \multicolumn{1}{|c|}{$(\mathbf{\%})$} & \multicolumn{1}{|c|}{ No } & \multicolumn{1}{|c|}{$(\%)$} \\
\hline 7. & Every woman is at risk of breast cancer & 203 & $(71.2 \%)$ & 82 & $(28.8)$ \\
\hline 8. & Family history of breast cancer is a risk factor & 150 & $(52.7)$ & 135 & $(47.4)$ \\
\hline 9. & $\begin{array}{l}\text { Menstruation before the age of 12 is a } \\
\text { risk factor breast cancer }\end{array}$ & 53 & $(15.1)$ & 242 & $(84.9)$ \\
\hline 10. & $\begin{array}{l}\text { Use of oral contraceptives is a risk factor for } \\
\text { Breast cancer }\end{array}$ & 104 & $(36.5)$ & 181 & $(63.5)$ \\
\hline 11. & $\begin{array}{l}\text { Poor breastfeeding increases the risk of breast } \\
\text { Factor }\end{array}$ & 124 & $(43.5)$ & 161 & $(56.5)$ \\
\hline 12. & $\begin{array}{l}\text { Late child bearing increases risk of breast } \\
\text { Cancer }\end{array}$ & 77 & $(27.0)$ & 208 & $(73.0)$ \\
\hline 13. & Childlessness increases breast cancer risk & 58 & $(20.4)$ & 227 & $(79.6)$ \\
\hline 14. & Obesity increases breast cancer risk & $\mathbf{8 5 8}$ & $\mathbf{( 3 7 . 6 )}$ & $\mathbf{1 4 2 2}$ & $\mathbf{( 6 2 . 4 )}$ \\
\hline & Total & & 186 & $(65.3)$ \\
\hline
\end{tabular}

Information in table 3, shows that $203(71.2 \%)$ knew that every woman is at risk of developing breast cancer, while $82(28.8 \%)$ answered no, $150(52.7 \%)$ said family history of breast cancer is a risk factor whereas $135(47.4 \%)$ said no, only $43(15.1 \%)$ knew that menstruation before the age of 12 is a risk factor for breast cancer while 242 did not know that menstruation before age 12 is a risk factor for breast cancer, $104(36.5 \%)$ knew that the use of oral contraceptives is a risk factor for breast cancer while $181(63.5 \%)$ did not know, $124(43.5 \%)$ knew that poor breastfeeding increases the risk of breast cancer whereas $161(56.5 \%)$ did not know, only $77(27.0 \%)$ knew that late childbearing increases the risk of breast cancer and 208 (73.0\%) did not know, 58 (20.4\%) knew that childlessness increases breast cancer risk while 227 (79.6\%) did not know and 99 (34.7\%) knew obesity increases the risk of breast cancer and $186(65.3 \%)$ did not know. On the whole there is a low level of knowledge of breast cancer risk factors among students in University of Uyo 858 (37.6\%).

Research Question 3: What is the level of knowledge of Breast Cancer Preventive Measures among students in University of Uyo? 
Knowledge of Breast Cancer Symptoms, Risk Factors, Preventive Measures and Management among Students in University of Uyo

Table4: Percentage Analysis of Knowledge of Breast Cancer Preventive Measures

\begin{tabular}{|l|l|l|l|l|l|}
\hline S/N & \multicolumn{1}{|c|}{ Items } & Yes & \multicolumn{1}{|c|}{$(\boldsymbol{\prime})$} & No & $(\%)$ \\
\hline 15. & $\begin{array}{l}\text { Regular breast screening helps in preventing } \\
\text { Breast cancer }\end{array}$ & 243 & $(85.3 \%)$ & 42 & $(14.7)$ \\
\hline 16. & BSE is a screening method for breast cancer & 210 & $(73.7)$ & 75 & $(26.3)$ \\
\hline 17. & BSE is done after menstruation & 128 & $(44.9)$ & 15 & $(55.1)$ \\
\hline 18. & Breast ultrasound is used to detect breast cancer & 195 & $(68.4)$ & 90 & $(31.6)$ \\
\hline 19. & $\begin{array}{l}\text { Mammography is the examination of the breast with a special } \\
\text { machine }\end{array}$ & 200 & $(70.2)$ & 85 & $(29.8)$ \\
\hline 20. & $\begin{array}{l}\text { Mammography can reveal early breast cancer } \\
\text { than BSE }\end{array}$ & 187 & $(65.6)$ & 98 & $(34.4)$ \\
\hline 21. & $\begin{array}{l}\text { Magnetic resonance imaging is a screening method for breast } \\
\text { cancer }\end{array}$ & 158 & $(55.4)$ & 127 & $(44.6)$ \\
\hline
\end{tabular}

Percentage analysis of research question 3 above reveals that $243(85.3 \%)$ agreed that regular breast screening helps in preventing breast cancer, $42(14.7 \%)$ answered no; $210(73.7 \%)$ knew that BSE is a screening method for breast cancer, 75 (26.3\%) did not know; 128 (44.9\%) knew BSE is done after menstruation, 157 (55.1\%) did not know; 195 (68.4\%) knew breast ultrasound is used to detect breast cancer, 90 (31.6\%) did not know; $200(70.2 \%)$ knew mammography is examination of the breast with a special machine, 85 (29.8\%) did not know; 187 (65.6\%) knew mammography can reveal early breast cancer than BSE while 98 (34.4\%) did not know; 158 (55.4\%) knew that MRI is a screening method for breast cancer while 127 (44.6\%) did not know. Generally, the knowledge for breast cancer preventive measures among students in University of Uyo was average 132 (66.2\%).

Research Question 4: What is the level of knowledge of Breast Cancer Management Approaches among Student in University of Uyo?

Table5: Percentage Analysis of Knowledge of Breast Cancer Management Approaches among Students in University of Uyo.

\begin{tabular}{|l|l|c|c|c|c|}
\hline S/N & \multicolumn{1}{|c|}{ Items } & Yes & $(\mathbf{\% )}$ & No & \multicolumn{1}{|c|}{$(\mathbf{\% )}$} \\
\hline 22. & Radiation therapy is used in the management of breast cancer & 199 & $(69.8 \%)$ & 86 & $(30.2)$ \\
\hline 23. & There are drugs used in managing breast cancer & 209 & $(73.3)$ & 76 & $(26.7)$ \\
\hline 24. & $\begin{array}{l}\text { Breast cancer can be managed by surgical } \\
\text { Removal of lump }\end{array}$ & 220 & $(77.2)$ & 65 & $(22.8)$ \\
\hline 25. & Surgical removal of the affected breast can cure breast cancer & 178 & $(62.5)$ & 107 & $(37.5)$ \\
\hline & Total & $\mathbf{8 0 6}$ & $\mathbf{( 7 0 . 7 )}$ & $\mathbf{2 8 4}$ & $\mathbf{( 2 9 . 3 )}$ \\
\hline
\end{tabular}

Percentage analysis of research question 4 shows that $199(69.8 \%)$ knew that radiation therapy is used in the management of breast cancer, $86(30.2 \%)$ did not know; $209(73.3 \%)$ knew there are drugs used in managing breast cancer while $76(26.7 \%)$ did not know; $220(77.2 \%)$ knew breast cancer can be managed by surgical removal of lump; 65 (22.8\%) did not know; and 178 (62.5\%) knew surgical removal of the affected breast can cure breast cancer where 107 (37.5\%) did not know. On the whole, there is high level of knowledge of breast cancer management approaches among students in University of Uyo 806 (70.7\%).

\subsection{Testing the Null Hypotheses}

Hypothesis one $\left(\mathbf{H o}_{1}\right)$ : Knowledge of Breast Cancer Symptoms is not significant among student in University of Uyo.

Table6: Chi-square Analysis of Knowledge of Breast Cancer Symptoms among Students

\begin{tabular}{|l|l|l|l|l|l|}
\hline S/N & \multicolumn{1}{|c|}{ Yes } & \multicolumn{1}{c|}{ No } & \multicolumn{1}{c|}{ Total } & \multicolumn{1}{c|}{$\mathbf{X}^{2}$ - cal } & $\mathbf{X}^{2}-$ crit \\
\hline 1. & $145(156.38)$ & $140(128.17)$ & 285 & & \\
\hline 2. & $177(156.38)$ & $108(128.17)$ & 285 & & \\
\hline 3. & $172(156.38)$ & $113(128.17)$ & 285 & & \\
\hline 4. & $162(156.38)$ & $123(128.17)$ & 285 & 18.09 & 11.09 \\
\hline 5. & $137(156.38)$ & $148(128.17)$ & 285 & & \\
\hline 6. & $148(156.38)$ & $137(128.17)$ & 285 & & \\
\hline Total & $\mathbf{9 4 1 ( 1 5 6 . 3 8 )}$ & $\mathbf{7 6 9}(\mathbf{1 2 8 . 1 7})$ & $\mathbf{2 8 5}$ & & \\
\hline
\end{tabular}

$\mathrm{n}=285, \mathrm{P}=0.5, \mathrm{df}=5$ 
Knowledge of Breast Cancer Symptoms, Risk Factors, Preventive Measures and Management among Students in University of Uyo

The analysis on table 6 shows that the calculated $x^{2}-$ value of 18.09 is greater than the critical $x^{2}-$ value of 11.09 at degree of freedom 5 and .05 significant level. The null hypothesis which states that knowledge of breast cancer symptoms is not significant among students in University of Uyo is rejected.

Hypothesis two $\left(\mathbf{H o}_{2}\right)$ : Knowledge of Breast Cancer Risk Factors is not significant among students in University of Uyo.

Table7: Chi-square Analysis of Knowledge of Breast Cancer Risk Factor among Students

\begin{tabular}{|l|l|l|l|l|l|}
\hline S/N & Yes & No & Total & $\mathrm{X}^{2}-$ cal & $\mathrm{X}^{2}-$ crit $^{-1}$ \\
\hline 7. & $203(107.5)$ & $82(177.75)$ & 285 & & \\
\hline 8. & $150(107.5)$ & $135(177.75)$ & 285 & & \\
\hline 9. & $43(107.5)$ & $242(177.75)$ & 285 & & \\
\hline 10. & $104(107.5)$ & $181(177.75)$ & 285 & 242.93 & 14.07 \\
\hline 11. & $124(107.5)$ & $161(177.75)$ & 285 & & \\
\hline 12. & $77(107.5)$ & $208(177.75)$ & 285 & & \\
\hline 13. & $58(107.5)$ & $227(177.75)$ & & & \\
\hline 14. & $99(107.5)$ & $186(177.75)$ & & & \\
\hline Total & 858 & 1422 & 2280 & & \\
\hline
\end{tabular}

$\mathrm{n}=285, \mathrm{P}=0.5, \mathrm{df}=7$

The analysis in table 7 shows that the calculated $x^{2}-$ value of 242.93 is greater than the critical $x^{2}-$ value of 14.07 at .05 significant level and 7 degree of freedom. The null hypothesis which states that knowledge of breast cancer risk factors is not significant among students in University of Uyo is rejected.

Hypothesis three $\left(\mathbf{H o}_{3}\right)$ : Knowledge of Breast Cancer Preventive Measures is not significant among Students in University of Uyo.

Table8: Chi-square Analysis of Knowledge of Breast Cancer Preventive Measures among Students

\begin{tabular}{|l|l|l|l|l|l|}
\hline S/N & Yes & No & Total & $\mathbf{X}^{2}$ - cal & $\mathbf{X}^{2}$ - crit \\
\hline 15. & $243(188.71)$ & $42(96.29)$ & 285 & & \\
\hline 16. & $210(188.71)$ & $75(96.29)$ & 285 & & \\
\hline 17. & $128(188.71)$ & $157(96.29)$ & 285 & & \\
\hline 18. & $195(188.71)$ & $90(96.29)$ & 285 & & \\
\hline 19. & $200(188.71)$ & $85(96.29)$ & 285 & & \\
\hline 20. & $187(188.71)$ & $98(96.29)$ & 285 & & \\
\hline 21. & $158(188.71)$ & $127(96.29)$ & 285 & & \\
\hline Total & $\mathbf{1 3 2 1}$ & $\mathbf{6 7 4}$ & $\mathbf{1 9 9 5}$ & & \\
\hline
\end{tabular}

$\mathrm{n}=285, \mathrm{P}=0.5, \mathrm{df}=6$

Analysis of table 8 shows that the calculated $x^{2}$ - value 128.61 is greater than the critical $x^{2}$ - value of 12.59 at df 14 and .05 level of significance. The null hypothesis which states that knowledge of breast cancer preventive measures is not significant among students in University of Uyo is rejected.

Hypothesis four $\left(\mathbf{H o}_{4}\right)$ : Knowledge of Breast Cancer Management Approaches is not significant among Students in University of Uyo.

Table9: Chi-square Analysis of Knowledge of Breast Cancer Management Approaches among Students

\begin{tabular}{|l|l|l|l|l|l|}
\hline S/N & Yes & No & Total & $\mathbf{X}^{2}$ - cal & $\mathbf{X}^{2}$ - crit \\
\hline 22. & $199(201.50)$ & $86(83.50)$ & 285 & & \\
\hline 23. & $209(201.50)$ & $76(83.50)$ & 285 & & \\
\hline 24. & $220(201.50)$ & $65(83.50)$ & 285 & & \\
\hline 25. & $178(201.50)$ & $107(83.50)$ & 285 & & \\
\hline Total & 806 & 334 & 1140 & & \\
\hline
\end{tabular}

$\mathrm{n}=285, \mathrm{P}=0.5, \mathrm{df}=3$

The analysis in table 9 shows that the calculated $x^{2}-$ value 16.20 is greater than critical $x^{2}-$ value of 7.81 at .05 significant level and degree of freedom 3. This means that the null hypothesis which state 
that knowledge of breast cancer management approaches is not significant among students in University of Uyo is rejected.

\subsection{Discussion of Findings}

In the course of this study, it is gathered that the level of knowledge of breast cancer symptoms among students in University of Uyo is on the average (55.1\%). The null hypothesis 1 (Ho1) was rejected because the calculated $x^{2}-$ value (18.09) was less than the critical value of (11.09). This shows that not every student has good knowledge of breast cancer symptoms. This result agrees with Omaka-Amari et al (2015) whose study showed average level of knowledge of breast cancer symptoms (55\%) among women in Ebonyi State. The study further revealed that the level of knowledge of breast cancer risk factors was generally low among student in University of Uyo $(37.6 \%)$. Few respondents knew that the use of oral contraceptives is a risk factor of breast cancer, majority $(63.5 \%)$ did not know. $56.5 \%$ poor breast feeding increases the risk of breast cancer and $65 \%$ did not know obesity increases risk of breast cancer. Only 20.4\% knew childlessness increases risk of breast cancer while $79.6 \%$ did not know. However, the null hypothesis on breast cancer risk factor was rejected as shown in the result table 7. The result deviates from Sambanje and Benford study in 2012 who observed widespread lack of knowledge on risk factors associated with breast cancer among University students in Angola. The result also contradicts Omaka-Amari et al., 2015 who observed that knowledge of breast cancer risk factors was average (42\%).

Furthermore, the result from the study revealed that knowledge of breast cancer preventive measures was significant among the group studied. However, the result in table 4 showed that $55.1 \%$ of the respondents did not know when and how to carryout Breast Self Examination. 44.6\% did not know that magnetic resonance imaging is a screening method for breast cancer. Generally, knowledge of breast cancer preventive measures among this group was average (66.2\%). Omaka et al., 2015 had similar result which reported that women had average knowledge (57\%) of breast cancer preventive measures. Irurhe et al however reported low level of knowledge of how and when to carry out Breast Self Examination. This may be as a result of the population which consisted secondary school students where knowledge may not be sufficient.

Finally, the study revealed that knowledge of breast cancer management approaches is high among students in University of Uyo. The result rejected the null hypothesis because the calculated $\mathrm{x}^{2}-$ value (16.20) was greater than the critical $x^{2}-$ value (7.81). The result is not but out of place. Most individuals know about how breast cancer can be managed medically especially by surgical removal of lumps. This result deviates from Omaka-Amari et al findings in 2015 who reported average level of knowledge $(52 \%)$ of breast cancer treatment options.

\section{CONCLUSION}

The outcome of this research work shows there is an average level of knowledge of breast cancer among students in University of Uyo and this should be improved upon. It is deduced that most students do not know and cannot identify the symptoms of breast cancer. Some of the risk factors which are influenced by health behaviours and certain lifestyles can be modified when adequate information is provided to individuals. For instance, when an individual knows that the use of oral contraceptives and make informed decisions to reduce the risk of developing the disease in his lifetime. Lastly although knowledge of preventive measures is average; most students did not know how and when to carry out Breast Self Examination which is common and cheaper than other preventive measures. This eventually hinders them from practicing Breast Self-Examination. Therefore, they should be educated on how and when to perform Breast Self Examination in order to make it effective in preventing breast cancer or detecting it earlier.

\section{RECOMMENDATIONS}

Based on the findings of the study, the following recommendations are made:

- Health education on Breast Cancer should be incorporated in general studies courses (GSTs). The school management and NGOs should from time to time organize public enlightenment campaign on breast health and breast cancer. 
Knowledge of Breast Cancer Symptoms, Risk Factors, Preventive Measures and Management among Students in University of Uyo

- The school management and government should encourage individuals to go for regular breast screening to help detect breast diseases at an early stage.

- The government and ministry of health should equip hospitals with machines to help in breast screening and this should be made affordable and assessible to all individuals.

- Students should be advised on breast self-examination before and after menstruation for detection of certain symptoms.

- Regular exercise and healthy food will also help in checking the risk of cancer.

\section{REFERENCES}

[1] Amajuoyi, I. J. \& Joseph, E. U. (2016). Research Report Writing. A Concise Approach, Aba. Windmill Publishing Company.

[2] American Cancer Society (2015). Cancer Facts and Statistic. Available at http://www.cancer.org/ research/cancerfactsatis/inde. Accessed on 19/11/2015.

[3] American Cancer Society (2015). The American Cancer Guidelines Screening for Breast Cancer: What's New? Journal of Advanced Practical Oncology 6(6) 508-510.

[4] Fragene, A. and Newman, L. A. (2015). Breast Cancer in Sub-Saharan African: How does it relate to breast cancer in African-American Women? Cancer. 103 (5): 1540-1550.

[5] Irurhe, N. Raji, S., Olowoyeye, A., Adeyomoye, A., Arogundade, K. et al (2012). Knowledge and awareness of Breast Cancer among Female Secondary School Students in Nigeria. Academic Journal of Cancer Research 5(1):01-05.

[6] Lakeshore Cancer Centre (2014). Breast Cancer Awareness. Available at www.lakeshorecancercentre. org/Accessed on 19/3/2015.

[7] Lester, J. (2007). Incidence, Risk Assessment, and Risk Reduction Strategies. Clin. J. Onco. Nurs. 11 (5): 619-22.

[8] Nwaneri, A., Osuala, E., Okpala, P., Emesownum, A. and Iheanacho, P. (2017). Knowledge and Awareness of Breast Cancer among Rural Women in Imo State. Nigerian Journal of Clinical Practice. $20(4): 489-494$.

[9] Omaka-Amari, L.,Ilo, C., Onwunaka, C. and Umoke, C. (2015). Demographic Differences in the Knowledge of Breast Cancer among Women in Ebonyi State, Nigeria. International Journal of Nursing \& Midwifery and Health Related Cases. 1(3):18-27.

[10] Panieri, E. (2012). Breast Cancer Screening in developing Countries. Best Pract. Res. Clin. Obstet. Gynaecol. 26 (2):283-290.

[11] Sambanje, M. N. \&. Benford, M. (2012). Breast Cancer Knowledge and Awareness among University Students in Angola. Pan African Medical Journal. 11(29):1540-70.

[12] Somdyala, N., Bradshaw, D. Gelderblom, W. and Parkin, D. (2010). Cancer incidence in rural population of South Africa. Int. J. Cancer. 127 (10):2420-9.

[13] World Health Organization (2015). Breast Cancer Prevention and Control. Available at http://www.who. int/cancer/detection/breastcancer/en/\#Accessedon March 19, 2015.

Citation: Grace Enomfon Akpan, et.al. " Knowledge of Breast Cancer Symptoms, Risk Factors, Preventive Measures and Management among Students in University of Uyo" International Journal of Sports and Physical Education (IJSPE), vol 6, no. 1, 2020, pp. 01-09. doi: http://dx.doi.org/10.20431/2454-6380.06010 01 .

Copyright: (0) 2020 Authors. This is an open-access article distributed under the terms of the Creative Commons Attribution License, which permits unrestricted use, distribution, and reproduction in any medium, provided the original author and source are credited. 